\title{
Uudet toimintamallit hyvinvoinnin ja terveyden edistämisessä
}

\author{
TANJA TILLES-TIRKKONEN, TOMI MÄKI-OPAS, MARJA VAARAMA, AIJA LOGREN, \\ SAARA PENTIKÄINEN, SANNI TIITINEN, SAKARI ILOMÄKI, \\ JUSSI PIHLAJAMÄKI, JAANA LAITINEN
}

Suomen Akatemian Strategisen tutkimuksen rahoittamissa tutkimushankkeissa - Osallistava hyvinvoinnin ja terveyden edistäminen (PROMEQ, STN \#303615), Stop Diabetes - tiedosta ratkaisuihin (StopDia, STN \#303537), ja Evidence-based health promotion at work (Promo@work \#303430) - kehitetään uusia toimintamalleja erilaisten ryhmien hyvinvoinnin edistämiseen. PROMEQ -tutkimushankkeessa kehitetään valtakunnalliseen, alueelliseen ja paikalliseen käyttöön laaja-alaista toimintamallia vaikuttavuusindikaattoreineen. Erilaisten kokeellisten interventioiden kohderyhminä ovat haavoittuvassa asemassa olevat ryhmät: kotona yksin asuvat iäkkäät, pitkäaikaistyöttömät, neet-nuoret ja maahanmuuttajat. Testatut toimintamuodot ovat osoittautuneet vaikuttaviksi. StopDia -tutkimushankkeessa etsitään vastausta keskeisen kansanterveydellisen haasteen, tyypin 2 diabeteksen ehkäisyyn. Lähtökohtana on nykyistä tehokkaampi diabetesriskissä olevien henkilöiden tavoittaminen ja terveyttä tukeviin elintapoihin ohjaaminen yksilön kannustamisen ja elinympäristön muutosten avulla. StopDia- tutkimushankkeessa on kehitetty muun muassa Pienet teot -digisovellus ja tuuppausta (nudging) hyödyntävä työkalupakki työpaikkojen käyttöön. Promo@work -hanke tuottaa terveyden edistämisen suositukset työpaikoille, tietoa näyttöön perustuvista elintapamuutoksen menetelmistä ja niiden soveltamismahdollisuuksista työpaikkaterveyden edistämiseen sekä ohjausvuorovaikutuksen hyvistä käytänteistä. Hankkeessa kehitetään ja testataan tutkimusnäyttöön perustuvaa mobiiliinterventiota erityisesti mikroyrittäjien hyvinvoinnin ja terveyden edistämiseksi. Yhteistä tutkimus- hankkeissa on yksilötasoa laajempi näkökulma. Niissä ei keskitytä vain terveyden vaan laajemmin hyvinvoinnin edistämiseen, ja yksilötekijöiden lisäksi huomio kiinnitetään myös rakenteellisiin tekijöihin. Tavoitteena on, että nämä erilaisiin teoreettisiin viitekehyksiin perustuvat mallit nivotaan osaksi jatkuvaa toimintaa uudenlaisia vaikutuskanavia hyödyntäen.

\section{HYVINYOINNIN JA TERVEYDEN EDISTÄMINEN - MISTÄ ON KYSE?}

Vallitsevaa terveyden edistämisen paradigmaa kritisoidaan keskittymisestä yksilöiden elintapoihin ja käyttäytymiseen sen sijaan, että parannettaisiin myös puutteellisia elinoloja ja muita terveyden ja hyvinvoinnin edellytyksiä (1-3). Suomessa tämä laajennus on politiikkatasolla jo tehty, mutta "hyvinvoinnin edistämisen" käsitteellinen epäselvyys haittaa toimintaa (2). Sosiaalisen laadun teoria yhdistettynä terveyden ja hyvinvoinnin kattavaan elämänlaadun teoriaan tarjoaa mahdollisuuden kokonaisvaltaiseen tarkasteluun $(4,5)$.

Yhteiskunnan sosiaalinen laatu toteutuu neljästä toisiinsa vaikuttavasta ulottuvuudesta, joita ovat sosioekonominen turvallisuus, sosiaalinen valtaistuminen, sosiaalinen osallisuus ja sosiaalinen koheesio. Nämä ulottuvuudet määrittävät henkilöiden toimijuutta ja vaikuttavat heidän pystyvyyteensä, terveyteensä ja elämänlaatuunsa. PROMEQ-hankkeessa mallia on testattu edustavalla suomalaisella väestöaineistolla, ja havaittu merkitseviä yhteyksiä sosiaalisen laadun eri ulottuvuuksien ja koetun terveyden ja elämänlaadun välillä. Tulokset osoittavat, että terveys ja hyvinvointi ovat moniulotteisia asioita, joihin 
vaikuttavat elinolojen ja muiden aineellisten ja yksilöllisten tekijöiden lisäksi myös yhteiskunnan rakenteisiin liittyvät tekijät, kuten osallisuus yhteiskunnan eri toimintoihin, valtaisuus vaikuttaa yhteiskunnan tapahtumiin sekä luottamus ja yhteiskunnan eheys. Sosiaalisen laadun malli vaikuttaa lupaavalta lähestymistavalta tarjoten hyvinvoinnin ja terveyden edistämiselle yhteisen viitekehyksen sekä hyvinvointi- ja terveyserojen tutkimiseen kaivatun kokonaisvaltaisen mallin (6). Mallin hyödynnettävyyteen tarvitaan kuitenkin vielä tutkimustietoa tueksi.

\section{HEIKOMMASSA ASEMASSA OLEVIEN ELÄMÄNLAATU JA TUEN TARPEET HYVINVOINNIN JA TERVEYDEN EDISTÄMISEN NÄKÖKULMASTA}

Aikaisemmasta tutkimuksesta tiedetään, että koulutuksella, ammattiasemalla ja tulotasolla on merkittävä rooli terveyteen ja hyvinvointiin (3). Monet hyvinvointi- ja terveysongelmat kasautuvatkin haavoittuvassa asemassa olevilla ryhmillä. Esimerkiksi nuorilla heikko koulutus, toimeentulon ongelmat, sosiaalisten suhteiden puute, kohonnut riski syrjäytyä yhteiskunnasta, sekä erilaiset elämänhallinnan ongelmat ovat yhteydessä psyykkiseen ja fyysiseen terveyteen (7). Pitkäaikaistyöttömillä on työllisiin verrattuna enemmän ongelmia fyysisessä ja psyykkisessä terveydessä sekä hyvinvoinnissa (8). Pakolaisilla hyvinvointi, terveys ja mielenterveys kytkeytyvät voimakkaasti toisiinsa. Lisäksi sosiaalisilla suhteilla ja traumaattisilla kokemuksilla on tärkeä rooli pakolaisten hyvinvoinnille (9). Vanhuksilla ongelmat liittyvät fyysiseen terveyteen, psyykkiseen toimintakykyyn, sosiaalisiin suhteisiin ja ympäristön esteettömyyteen sekä palvelujen saavutettavuuteen ja saatavuuteen (10)

Haavoittuvassa asemassa olevien ryhmien, kuten koulutuksen ja työelämän ulkopuolelle olevien nuorten (NEET), pitkäaikaistyöttömien, pakolaisten ja yksin asuvien ikäihmisten tilanteita ei tunneta vielä kovin hyvin. Onkin mahdollista, etteivät perinteiset hyvinvoinnin ja terveyden edistämisen lähestymistavat tavoita heitä. Osallistava terveyden ja hyvinvoinnin edistäminen (PROMEQ, www.promeq.fi) -tutkimus perustuu edellä esitettyyn laajaan hyvinvoinnin käsitteeseen, ja pyrkii syventämään ymmärrystä väestön ja etenkin edellä mainittujen ryhmien hyvinvoinnista ja terveydestä sekä niiden taustamekanismeista. PROMEQ:in tavoitteena on tuottaa tietoa vaikuttavien hyvinvointia ja terveyttä edis- tävien toimien suunnitteluun, kohdentamiseen ja arviointiin.

Hankkeen ensimmäisessä vaiheessa tutkittavien ryhmien elämänlaatua on analysoitu kerätyn kyselyaineiston (vuosi 2017, N=1253) ja Maailman terveysjärjestön elämänlaatumittarin lyhyen version (WHO:n QOL-Bref) avulla. WHO Qol-Bref mittari sisältää 26 kysymystä, joista 2 mittaavat yleistä elämänlaatu ja terveyttä sekä 24 kysymystä kuvaavat elämänlaadun neljää eri ulottuvuutta: fyysinen, psyykkinen, sosiaalinen ja elinympäristö (aineelliset elinolot, palvelujen saatavuus, ympäristön terveellisyys ja turvallisuus). Alustavien tulosten mukaan (11) NEET:eillä, pitkäaikaistyöttömillä, pakolaisilla ja ikäihmisillä oli elämänlaadun kaikilla neljällä ulottuvuudella huonompi elämänlaatu kuin suomalaisella väestöllä keskimäärin. NEET:eillä ja pitkäaikaistyöttömillä ongelmat ilmenivät pääosin elämänlaadun psyykkisellä ulottuvuudella, pakolaisilla psyykkisellä ja ympäristöllisellä ulottuvuudella, ja ikäihmisillä fyysisellä ja psyykkisellä ulottuvuudella. Rahojen riittävyys ja kyky nauttia elämästä olivat kaikille ryhmille hyvän elämänlaadun kannalta tärkeitä. Muita elämänlaatua edistäviä tekijöitä olivat: NEET:illä tyytyväisyys liikkumismahdollisuuksiin ja ihmissuhteisiin, pitkäaikaistyöttömillä tyytyväisyys omaan ulkomuotoon ja sosiaali- ja terveyspalveluiden saatavuuteen, pakolaisilla hyvä itsetunto, sekä iäkkäillä hyvä toimintakyky ja riittävät vapaa-ajan harrastusmahdollisuudet.

Näiden alustavien tulosten perusteella näyttää siltä, että heikommassa asemassa olevien väestöryhmien hyvinvoinnin edistäminen edellyttää rakenteellisen tason toimia etenkin päivittäisen toimeentulon turvaamiseen liittyen. Lisäksi tulisi kohdistaa räätälöityjä toimia NEETeillä liikkumismahdollisuuksien parantamiseen (esim. julkisen liikenteen ilmaiset tai subventoidut matkakortit) ja sosiaalisten suhteiden tukemiseen, pitkäaikaistyöttömillä itsetunnon tukemiseen ja integroitujen työvoima-, sosiaali- ja terveyspalvelujen turvaamiseen, pakolaisilla itsetunnon tukemiseen ja aineellisiin elinoloihin, sekä iäkkäillä päivittäisen toimintakyvyn ylläpitämiseen, yksinäisyyden lieventämiseen ja vapaa-ajan harrastusmahdollisuuksien turvaamiseen. PROMEQtutkimus jatkuu tehtyjen interventioiden vaikuttavuuden arviointina ennen-jälkeen asetelmassa, ja tulokset julkaistaan kevään 2019 aikana. 
TEHOKKAAMPI TAVOITTAMINEN, DIGITAALISET OHJAUSMALLIT JA TYÖYMPÄRISTÖTUUPPAUS AVUKSI TYYPIN 2 DIABETERSEN EHKÄISYYN

Tyypin 2 diabetes on keskeinen kansanterveydellinen haaste, jonka aiheuttamat yhteiskunnalliset kustannukset ovat merkittävät. Suomessa on noin 300000 tyypin 2 diabetesta sairastavaa henkilöä ja arviolta noin 20-30 prosenttia on kohonneessa riskissä sairastua. Kohonneessa riskissä olevien henkilöiden tunnistamiseen voidaan käyttää tutkimusnäyttöön pohjautuvaa FINDRISK-diabetesriskitestiä (12). Tieto erilaisten viestintäkanavien tehokkuudesta kohonneessa diabetesriskissä olevien tavoittamiseen on kuitenkin vajavaista. ItäSuomen yliopiston, THL:n ja VTT:n toteuttamassa StopDia - tutkimushankkeessa (www.stopdia.fi) yhtenä tavoitteena onkin tutkia erilaisten kanavien tehoa. Vuosien 2017-2018 aikana tutkimushankkeessa on hyödynnetty useita erilaisia kanavia viestittäessä diabetesriskitestistä ja kannustaen sen tekemiseen. StopDia - tutkimushankkeen alustavien tulosten mukaan tehokkaimpia viestintäkanavia kohonneessa tyypin 2 diabetesriskissä olevien tavoittamiseen ovat olleet lehtiartikkelit, sukulaisten ja tuttavien kautta saatava viesti, työpaikkojen kautta tapahtuva viestintä ja sosiaalinen media. Eri viestintäkanavien merkityksen todettiin vaihtelevan sosiodemografisten taustatekijöiden, iän, sukupuolen, työtilanteen ja koulutustason mukaan. Esimerkiksi miehillä sukulaisilta ja tuttavilta saatu kannustus oli tehokkaampi viestintäkanava, kun naisilla, joilla sen sijaan sosiaalinen media oli merkityksellisempi.

Kohonneessa tyypin 2 diabetesriskissä olevien tavoittaminen on tärkeää, sillä elintapaohjauksen on todettu olevan tehokasta hidastamaan sairauden puhkeamista tai ehkäisevän sen jopa kokonaan $(13,14)$. Elintapaohjaus ei ole kuitenkaan riittävästi juurtunut osaksi terveydenhuoltoa ja muita toimintaympäristöjä. StopDia - tutkimushankkeessa tutkitaan osana terveydenhuollon toimintaa satunnaistetun, kontrolloidun tutkimusasetelman avulla digisovelluksen sekä digitaalisella sovelluksella täydennetyn ryhmäohjauksen vaikuttavuutta ja toimivuutta. Lisäksi tutkimushankkeessa toteutetaan tuuppausta hyödyntävä ympäristöinterventio. StopDia-tutkimuksen interventiossa on vahva käyttäytymistieteellinen tausta. Osana terveydenhuollon toimintaa toteutettavissa interventioissa hyödynnetään muun muassa Itsemääräämisteoriaa (15) ja käyttäytymismuutostekniikoita (16). Tutkimushankkeessa on kehitetty Pienet teot -digisovellus hyödyntää habit -pohjaista ideologiaa $(17,18)$. Sovellus sisältää yli 450 pientä hyvinvoinnin edistämiseen tähtäävää tekoa, joita esitetään käyttäjällä teemoittain ja joista käyttäjä voi valita itselleen mahdollisesti sopivia tekoja toteutettavaksi. Sovelluksen käytön alustavat tulokset ovat lupaavia ja sen vaikuttavuudesta ja toimivuudesta saadaan lopullisia tuloksia vuoden 2019 aikana.

Tuuppauksilla tarkoitetaan valintaympäristön muokkaamista siten, että ihmisen käyttäytyminen muuttuu ennakoitavalla tavalla ilman, että vaihtoehtoja on vähennetty tai valinnasta aiheutuvia kustannuksia merkittävästi muutettu (19). Tuuppauksessa hyödynnetään ymmärrystä siitä, että ihmisen toimintaa ohjaavat reflektiivisten prosessien lisäksi automaattiset, osin tiedostamattomat prosessit (20). Erityisesti 2010luvulla on tehty runsaasti tuuppausta hyödyntäviä terveydenedistämisen interventioita, joiden tulokset ovat olleet pääosin lupaavia (21). Tutkimuksissa on esimerkiksi onnistuttu vähentämään energiansaantia ja lisäämään arkiaktiivisuutta. StopDia-tutkimushankkeessa sovelletaan tuuppauksen periaatteita työpaikoilla työntekijöiden terveyden edistämiseen. Tavoitteena on edistää hyviä työpäivän aikaisia ruokailu- ja liikuntatottumuksia työympäristöä muokkaamalla. Tutkimushankkeessa on koottu yhteen aiempaan tutkimuskirjallisuuteen ja tutkimushavaintoihin pohjautuvia, työpaikoille soveltuvia tuuppausnäkökulmaa hyödyntäviä toimia ns. 'Tuuppauspakiksi'. Yhteensä 16 työpaikkaa ja yli 100 toimipistettä kolmen maakunnan alueelta osallistuu tutkimukseen. Tuuppauspakista on valittu kunkin työpaikan kanssa kokeiltavaksi soveltuvat tuuppaustoimet. Vuoden kestävä interventio on käynnissä. Intervention myötä saadaan tietoa tuuppaustoimien hyväksyttävyydestä ja soveltuvuudesta erilaisilla työpaikoille sekä vaikutuksista työaikaisiin ruokailu- ja liikkumistottumuksiin.

\section{ITSEMÄÄRÄÄMISTEORIA JA KÄYTTÄYTYMISEN MUUTOS- TEKNIIKAT MOBIILISOVELLUKSELLA TOTEUTETTAVASSA OHJAUKSESSA}

Markkinoilla on lukuisia mobiilisovelluksia jotka tähtäävät käyttäjän terveyden ja hyvinvoinnin edistämiseen, mutta vain murto-osa niistä perustuu tutkimustietoon elintapakäyttäytymisestä ja muutosprosessia edistävistä tekijöistä. Esimerkiksi suosituimmista liikunnan lisäämiseen tähtää- 
vistä mobiilisovelluksista noin puolet keskittyy tietojen ja taitojen lisäämiseen (22). Muutoksessa harvoin on kyse puhtaasti tiedollisten ja taidollisten puutteiden poistamisesta. Promo@Work -hankkeessa kehitettiin aikaisempien meta-analyysien perusteella mikroyrittäjien työstä palautumista ja työkykyä tukeva mobiilisovellus, jossa itsemääräämisteoria ja toimiviksi osoitetut käyttäytymisen muutostekniikat yhdistettiin terveyskäyttäytymistä koskevaan substanssisisältöön.

Katsauksissa vaikuttaviksi todettuja käyttäytymisen muutostekniikoita ovat: 1) tavoitteen asettelu, 2) itsetarkkailu, 3) palautteen antaminen, 4) sosiaalinen vertailu ja tuki, sekä 5) tiedon ja ohjeiden antaminen (23-27). Lisäksi pyrittiin varmistamaan, että muutostekniikat huomioivat yksilön ja hänen ympäristönsä kattavasti. Tässä käytettiin apuna Behavior Change Wheel -mallia ja etenkin siihen sisältyvää ajatusta "toimintasysteemistä" käyttäytymisen osatekijöiden kuvaajana. Mallin ajatuksena on, että toimintaan (behavior) voidaan vaikuttaa vain siihen liittyvien kykyjen (capabilities), motivaation (motivation) ja mahdollisuuksien (opportunities) kautta (COM-B-malli). (28) Itsemääräämisteoria itsessään ei tarjoa yksiselitteistä perustaa tiettyjen muutostekniikoiden valintaan. Päällisin puolin sama käyttäytymisen muutostekniikka voi olla linjassa itsemääräämisteorian kanssa tai sitä vastaan riippuen siitä, miten se on toteutettu. (29) Siksi mobiilisovelluksen kehitystyössä kiinnitettiin erityistä huomiota siihen, että toteutustavat vastaavat itsemääräämisteoriassa määriteltyihin toiminnan säätelyn perusteisiin.

Itsemääräämisteoriassa ihminen nähdään luonnostaan aktiivisena, motivoituneena ja kehittyvänä. Toiminnan säätely voi perustua ulkoisiin tekijöihin, kuten rangaistuksiin tai palkkioihin, tai se voi olla sisäsyntyistä: toiminta itsessään tuottaa nautintoa. Kolmantena säätely voi perustua sisäistettyyn motivaatioon: toiminta tähtää yksilölle itselleen tärkeiden päämäärien saavuttamiseen. Toiminnan säätelyn sisäistämistä kuvataan kolmivaiheisen mallin avulla. Ensimmäisessä, niin sanotussa sisäisesti pakotetun säätelyn (introjection) vaiheessa ihminen mukautuu ulkoisiin odotuksiin ja noudattaa niitä pitääkseen yllä omanarvontuntoaan ja välttääkseen syyllisyydentunteita. Toisessa, samaistumisen (identification) vaiheessa ihminen samaistuu itse toimintaan liittyvien arvojen kanssa ja hy- väksyy toiminnan ja arvot osaksi omaa itseään. Viimeisessä eli integraatiovaiheessa ihminen puolestaan yhdistää aiemmassa vaiheessa saavutetun samaistumisen osaksi identiteettinsä ydinarvoja ja -käytäntöjä. Mitä sisäistetympää toiminnan säätely on, sitä todennäköisemmin ihmiset kykenevät tekemään elintapamuutoksia ja ylläpitämään niitä. $(30,31)$

Myös ihmisen perustarpeiden huomioiminen ja niihin vastaaminen ovat olennaisia toiminnan säätelemisessä. Itsemääräämisteorian mukaan ihmisen motivaation perustana ovat kolme psykologista perustarvetta: 1) autonomian tarve, 2) kompetenssin tarve ja 3) liittymisen tarve. Autonomialla tarkoitetaan kokemusta itsestä toiminnan lähteenä ja mahdollisuudesta vapaaseen tahtoon toiminnassa. Kompetenssi tarkoittaa kokemusta siitä, että osaa ja pystyy saavuttamaan haluamiaan asioita ja hyödyntämään omia kykyjään. Liittymisen tarpeella puolestaan tarkoitetaan ihmisen tarvetta olla yhteydessä muihin ihmisiin ja tulla ymmärretyksi ja arvostetuksi. $(15,30,31)$

Mobiilisovelluksen kehitystyössä valittiin käyttäytymisen muutostekniikoita ja pohdittiin niiden toteutustapoja siten, että ne a) ovat aiempien tutkimusten valossa vaikuttavia, b) ottavat monipuolisesti huomioon kaikki COM-B-mallin osa-alueet, ja c) vastaavat itsemääräämisteoriassa määriteltyihin toiminnan säätelyn perusteisiin.

\section{YHTEENVETONA}

Hyvinvoinnin ja terveyden edistämisen vahvistaminen on ollut terveyspolitiikan tavoitteena Suomessa jo yli kaksikymmentä vuotta. Keskeisiä tavoitteina ovat olleet $\mathrm{mm}$. kroonisten sairauksien ehkäisy ja terveydelle edullisten elintapojen ja elinolojen edistäminen. Nykyiset hyvinvoinnin ja terveyden edistämisen haasteet ovat luonteeltaan monimutkaisia esimerkiksi terveyden ja hyvinvoinnin eriarvoisuus, lihavuus, tyypin 2 diabetes, terveellisten elintapojen omaksuminen ja ylläpitäminen, sosiaali- ja terveyspalveluiden muutos (SOTE), sosiaaliset ongelmat ja monikulttuurisuuden lisääntyminen. Yksilöiden hyvinvointi ja terveys eivät ole missään yhteiskunnissa seurausta vain epäterveellisistä elintavoista tai motivaation ja vastuun puutteesta, vaan taustalla on myös monia rakenteellisia yhteiskunnallisia tekijöitä kuten köyhyys ja osattomuus.

Uuden hyvinvoinnin ja terveyden edistämisen 
ns. "mallin 2.0" tulisi sekä puuttua rakenteellisiin tekijöihin (syiden syihin; juurisyihin), että voimaannuttaa ja valtaistaa ihmisiä. Kaikkien kykyä ja taitoja hyvään elämään ja terveyteen sekä näitä tukeviin valintoihin tulisi tukea. Olennaista on ymmärtää yksilöiden toimijuuden ja yhteiskunnan rakenteiden välisen vuorovaikutuksen perustavanlaatuinen merkitys hyvinvoinnille ja terveydelle. Ihmisen mahdollisuuksia ylläpitää ja edistää omaan terveyttään ja hyvinvointiaan tulisi tarkastella siinä kontekstissa, jossa henkilö elää ja viettää suurimman osan päivittäisestä elämästään. Osallisuus näkyy toimijuutena, ja yhteiskunnan rakenteet säätelevät sen toteutumisen mahdollisuuksia ja astetta. Osallisuus sosiaalisissa verkostoissa ja mahdollisuus vaikuttaa yhteiskunnan kehitykseen ja itselle tärkeitä asioita koskevaan päätöksentekoon ovat hyvinvoinnin kulmakiviä. Hyvinvoinnin ja terveyden edistämisen mallin 2.0 kehittäminen vaatii ilmiöiden monimutkaisuuden takia kokonaisvaltaista ja systeemistä lähestymistapaa hyvinvoinnin ja terveyden eriarvoisuuden kysymyksiin, jotta toimenpiteet kohdistetaan vaikuttavalla tavalla myös ilmiöiden taustalla oleviin tekijöihin. Perinteisten menetelmien rinnalle tarvitaan uusia ja myös digitaalisia menetelmiä (kuten Pienet teot - ja Palaudu -digisovellukset), jotka kannustavat ihmisiä edistämään hyvinvointiaan ja terveyttään. Perinteinen terveyden edistäminen on keskittynyt ylhäältä alaspäin suuntautuvaan terveysvalistukseen, mutta uusien osallistavien toimintamallien on noustava kohderyhmien tarpeista eli alhaalta ylöspäin.

\section{LÄHTEET:}

1. Green J, Tones K, Cross R, ym. Health Promotion - Planning \& Strategies. London: Sage; 2015.

2. Karvonen S, Sihto M. Terveyden edistäminen ja eriarvoisuus - lähestymistapoja ja ratkaisuja, Terveyden ja hyvinvoinnin laitos, Teema 24;2017.

3. Lahelma E, Rahkonen O. Sosiaalinen rakenne ja terveys. Teoksessa: Karvonen S, Kestilä L, MäkiOpas T, toim. Terveyssosiologian linjoja. Helsinki: Gaudeamus; 2017, 19-39.

4. Van Der Maesen L, Walker A. Social Quality. From Theory to Indicators: Palgrave Macmillan: New York; 2012.

5. Pieper R, Vaarama M, Karvonen S. Social Sustainability: Theory, Model and Measurement - The SOLA approach. 2016. PROMEQ Working paper https://www.promeq.fi/ loader.aspx?id=3b8dde21-2cac-4859-9566b11f031bb1f9 [viitattu 09.02.2018].

6. Vaarama M. Hyvinvoinnin ja terveyden edistäminen - Mistä on kyse? Sosiaalilääketieteen päivät 2018, tieteellinen esitys löytyy PROMEQhankkeen www-sivuilta: https://www.promeq.fi/ news/Terveyden-edistamisesta-kokonaisvaltaiseenhyvinvoinnin-edistamiseen/39387/3a7679da-8c954f27-8e26-c7a986218b8e.

7. Karvonen S, Kestilä L. Nuorten aikuisten syrjäytymisvaaraan liittyvä huono-osaisuus. Teoksessa: Vaarama M, toim. Suomalaisten hyvinvointi 2014. Terveyden ja hyvinvoinnin laitos; 2014, 160-177.

8. Hultman B, Hemlin S, Hörnquist J. Quality of Life among unemployed and employed people in northern Sweden. Are there any differences? Work, 2014;26:45-76.

9. Aziz, IA, Hutchinson CV, Maltby J. Quality of life of syrian refugees living in camps in the kurdistan

region of iraq. PeerJ 2014;11:e670.

doi.10.7717/peerj.670.

https://doi.org/10.7717/peerj.670

10. Vaarama M, Moisio P, Karvonen S. Suomalaisten hyvinvointi (HYPA) 2014. Helsinki: Terveyden ja hyvinvoinnin laitos; 2014.

11. Mäki-Opas T, Vaarama M. Heikommassa asemassa olevat ja heidän tarpeensa hyvinvoinnin ja terveyden edistämisen näkökulmasta, Sosiaalilääketieteen päivät 2018, tieteellinen esitys löytyy PROMEQ-hankkeen wwwsivuilta: https://www.promeq.fi/news/ Terveyden-edistamisesta-kokonaisvaltaiseenhyvinvoinnin-edistamiseen/39387/3a7679da-8c954f27-8e26-c7a986218b8e

12. Lindström J, Tuomilehto J. The diabetes risk score: a practical tool to predict type 2 diabetes risk. Diabetes Care 2003;26:725-731.

https://doi.org/10.2337/diacare.26.3.725

13. Tuomilehto J, Lindström J, Eriksson JG, ym. Prevention of Type 2 Diabetes Mellitus by Changes in Lifestyle among Subjects with Impaired Glucose Tolerance. N Engl J Med 2001;3:13431350. https://doi.org/10.1056/NEJM200105033441801

14. Lindström J, Peltonen M, Eriksson JG, ym. Improved lifestyle and decreased diabetes risk over 13 years: long-term follow-up of the randomised Finnish Diabetes Prevention Study (DPS). Diabetologia 2013;24:284-293. doi: 10.1007/ s00125-012-2752-5. https://doi.org/10.1007/s00125-012-2752-5

15. Ryan R, Deci E. Self-determination theory and the facilitation of intrinsic motivation, social development, and well-being. Am Psychol 2000;55:68-78.

https://doi.org/10.1037/0003-066X.55.1.68 
16. Michie S, Richardson M, Johnston M, ym. The behavior change technique taxonomy (v1) of 93 hierarchically clustered techniques: building an international consensus for the reporting of behavior change interventions. Ann Behav Med 2013;46:81-95. doi: 10.1007/s12160-013-9486-6. https://doi.org/10.1007/s12160-013-9486-6

17. Wood W, Rünger D. Psychology of Habit. Annu Rev Psychol, 2016;67:289-314. doi: 10.1146/annurev-psych-122414-033417. https://doi.org/10.1146/annurevpsych-122414-033417

18. Lally P, Gardner B. Promoting habit formation. Health Psychology Review 2013;7:137-158. doi.org/10.1080/17437199.2011.603640. https://doi.org/10.1080/17437199.2011.603640

19. Thaler R, Sunstein C. Nudge: Improving decisions about health wealth and happiness. Revised and expanded edition. Lontoo: Penguin Books; 2009.

20. Marteau T. Changing minds about changing behaviour. The Lancet 2018;391:116-117. https://doi.org/10.1016/S0140-6736(17)33324-X

21. Arno A, Thomas S. The efficacy of nudge theory strategies in influencing adult dietary behaviour: a systematic review and meta-analysis. BMC Public Health 2016;16:676-686. doi: 10.1186/s12889-016-3272-x. https://doi.org/10.1186/s12889-016-3272-x

22. Conroy D, Yang C, Maher J. Behavior change techniques in top-ranked mobile apps for physical activity. Am J Prev Med 2014;46:649-652. doi: 10.1016/j.amepre.2014.01.010. https://doi.org/10.1016/j.amepre.2014.01.010

23. Silva M, Marques M, Teixeira P. Testing theory in practice: The example of self-determination theory-based interventions. The European Health Psychologist 2014;16:171-180.

24. Michie S, Abraham C, Whittington C, ym. Effective techniques in healthy eating and physical activity interventions: A meta-regression. Health Psychol 2009;28:690-701.

https://doi.org/10.1037/a0016136

25. Schoeppe S, Alley S, Van Lippevelde W, ym. Efficacy of interventions that use apps to improve diet, physical activity and sedentary behaviour: A systematic review. Int J Behav Nutr Phys Ac 2016;7:127. https://doi.org/10.1186/s12966-016-0454-y

26. Webb T, Joseph Y, Yardley L, ym. Using the internet to promote health behavir change: a systematic review and meta-analysis of the impact of theoretical basis, use of behavior change techniques, and mode of delivery on efficacy. J Med Internet Res 2010;12:e4. doi: 10.2196/jmir.1376. https://doi.org/10.2196/jmir.1376

27. Rivera J, McPherson A, Hamilton J, ym. Mobile apps for weight management: A scoping review. JMIR Mhealth Uhealth 2016;4:e87. doi: $10.2196 /$ mhealth.5115. https://doi.org/10.2196/mhealth.5115

28. Michie S, van Stralen M, West R. The behaviour change wheel: A new method for characterising and designing behaviour change interventions. Implement Sci 2011;6:42. doi: 10.1186/1748-5908-6-42.

https://doi.org/10.1186/1748-5908-6-42

29. Hagger M, Hardcastle S. Interpersonal style should be included in taxonomies of behavior change techniques. Front Psychol 2014;5:254. doi: 10.3389/fpsyg.2014.00254. https://doi.org/10.3389/fpsyg.2014.00254

30. Deci E, Ryan R. The "What" and "Why" of Goal Pursuits: Human Needs and the SelfDetermination of Behavior. Psychological Inquiry 2000:11;227-268. https://doi.org/10.1207/S15327965PLI1104_01

31. Deci E, Ryan R. Self-Determination Theory. In Van Lange P.A.M., Kruglanski A.W., Higgins E.T. (eds.) Handbook of Theories of Social Psychology. London, Thousand Oaks, New Delhi, Singapore: SAGE Publications; 2012, 416-437.

\section{TANJA Tilles-TirkKonen}

TtT, Tutkijatohtori

Itä-Suomen yliopisto, kansanterveystieteen ja kliinisen ravitsemustieteen yksikkö

\section{Tomi Mäki-Opas \\ Dosentti, FT, tutkimusjohtaja \\ Itä-Suomen yliopisto, \\ Yhteiskuntatieteiden laitos}

\section{Marja VaARama \\ Professori, Promeq - tutkimushankkeen päätutkija \\ Itä-Suomen yliopisto, Yhteiskuntatieteiden ja kauppatieteiden tiedekunta}

\section{AiJA LOGREN \\ YTM, tutkija, tohtoriopiskelija \\ Tampereen yliopisto, \\ Yhteiskuntatieteiden tiedekunta}

\author{
SaAra Pentikäinen \\ TtM (väit.), tutkija \\ Teknologian tutkimuskeskus VTT Oy
}

\section{SANNi TiITINEN \\ YTT, tutkijatohtori \\ Tampereen yliopisto, \\ Yhteiskuntatieteiden tiedekunta}

\section{SAKARI ILOMÄKI \\ YTM, tutkija, tobtoriopiskelija \\ Tampereen yliopisto, \\ Ybteiskuntatieteiden tiedekunta}

Jussi PihlajamäKI

Professori, Dekaani, StopDia- tutkimushankkeen päätutkija

Itä-Suomen yliopisto, terveystieteiden tiedekunta

JAANA LAITINEN

FT, johtava asiantuntija,Promo@Work -tutkimushankkeen päätutkija

Työterveyslaitos 